\title{
Estimating the mental health costs of racial discrimination
}

\author{
Amanuel Elias ${ }^{*}$ (ID) and Yin Paradies
}

\begin{abstract}
Background: Racial discrimination is a pervasive social problem in several advanced countries such as the U.S., U.K., and Australia. Public health research also indicates a range of associations between exposure to racial discrimination and negative health, particularly, mental health including depression, anxiety, and post-traumatic stress disorder (PTSD). However, the direct negative health impact of racial discrimination has not been costed so far although economists have previously estimated indirect non-health related productivity costs. In this study, we estimate the burden of disease due to exposure to racial discrimination and measure the cost of this exposure.

Methods: Using prevalence surveys and data on the association of racial discrimination with health outcomes from a global meta-analysis, we apply a cost of illness method to measure the impact of racial discrimination. This estimate indicates the direct health cost attributable to racial discrimination and we convert the estimates to monetary values based on conventional parameters.

Results: Racial discrimination costs the Australian economy 235,452 in disability adjusted life years lost, equivalent to $\$ 37.9$ billion per annum, roughly 3.02\% of annual gross domestic product (GDP) over 2001-11, indicating a sizeable loss for the economy.

Conclusion: Substantial cost is incurred due to increased prevalence of racial discrimination as a result of its association with negative health outcomes (e.g. depression, anxiety and PTSD). This implies that potentially significant cost savings can be made through measures that target racial discrimination. Our research contributes to the debate on the social impact of racial discrimination, with implications for policies and efforts addressing it.
\end{abstract}

Keywords: Burden of disease, DALY, Health cost, Racial discrimination, Australia

\section{Background \\ Introduction}

Existing scholarship acknowledges the cost of racial discrimination and its disproportionate bearing on racial minorities [1-3]. However, the economic consequences experiences of racial discrimination (EOD) extend beyond the immediate targets to those witnessing discrimination [4] and even to the perpetrators themselves [5-7]. Flow on effects can occur for the targets' immediate and/or extended families [8-10], communities, and government institutions that are tasked with combating discrimination. At an aggregate level, the country can incur losses in terms of direct healthcare expenditures arising from the health-related impact of racism and

\footnotetext{
* Correspondence: amanuel.h@deakin.edu.au

Alfred Deakin Institute for Citizenship \& Globalization, Faculty of Arts and

Education, Deakin University, 221 Burwood HWY, Burwood, VIC 3125,

Australia
}

(c) The Author(s). 2016 Open Access This article is distributed under the terms of the Creative Commons Attribution 4.0 International License (http://creativecommons.org/licenses/by/4.0/), which permits unrestricted use, distribution, and reproduction in any medium, provided you give appropriate credit to the original author(s) and the source, provide a link to the Creative Commons license, and indicate if changes were made. The Creative Commons Public Domain Dedication waiver (http://creativecommons.org/publicdomain/zero/1.0/) applies to the data made available in this article, unless otherwise stated. ployment discrimination.

The purpose of this study is to cost the negative mental health outcomes associated with exposure to EOD. We apply a step by step costing method to estimate the health impact of EOD, focusing on four key health outcomes including depression, anxiety, post-traumatic stress disorder (PTSD) and psychological disorder.

In this and the next section, we discuss related literature and the methods involved including the data we utilise in our analysis. Then, we present the results reporting burden of disease estimates, DALYs and health cost estimates. We also report a sensitivity analysis, taking three scenarios, each assuming alternative parameters. We then discuss the findings, before presenting a brief conclusion. 


\section{Related research}

Although there has been research on employment-related costs of discrimination [11], intangible costs that manifest in terms of pain and suffering arising from the physical and psychological illnesses may also be considerable. A wide body of evidence has documented the negative health outcomes associated with experiences of racial discrimination (EOD) [12-16]. However, to our knowledge, no previous study has so far estimated these health-related costs in monetary terms. In this study, we attempt to fill this gap by estimating the dollar value of these intangible health related costs from a societal perspective, focusing, particularly, on mental illnesses. Using Australian prevalence data and association data from a recent meta-analysis [14], we calculate burden of disease (BoD) estimates in terms of disability adjusted life years (DALYs) for outcomes with the requisite data.

Previously, estimations of the economic cost of EOD followed the neoclassical approach which generally focuses on indirect costs related to productivity loss as a result of discrimination premiums $[17,18]$. In labour economics, these costs are measured as differentials in wages, earnings, employment, promotion and labour supply (see [19-21] for reviews). Similarly, literature at the intersection of law and economics has been limited to detecting evidence of racial discrimination rather than estimating its human and social impact. Another literature related to the housing market, measures EOD-related costs to minority group customers in terms of potential indirect costs, associated with higher prices and limited services [22, 23].

So far, only a handful of studies have gone beyond a focus on the indirect microeconomic impact in estimating the cost of EOD. Although these studies are also based on indirect productivity loss (i.e., opportunity costs to businesses), they have attempted to estimate the potential aggregate effect of EOD in an economy [24-26]. The estimations attribute the costs to foregone wages for minorities, and indirectly measure losses in national output from an industry perspective.

\section{Health cost estimation}

Depending on the prevalence of EOD and the degree of association between EOD and health outcomes, EOD can also be seen as a public health issue as it can affect the overall wellbeing and quality of life of a society. This aspect of the cost of EOD can be assessed using cost of illness methods which are widely utilised in health economics. Using this approach, the cost of EOD can be conceptualised in terms of health outcomes from an individual/societal perspective where the health burden is largely borne by individuals, and cumulatively by a society, in the form of physical and mental illnesses.

Following the cost of illness literature [27-29], the cost of EOD can either be determined by identifying the cost components from different perspectives (industry/ business, government, or society) or classified into three distinct components: direct costs, indirect costs and intangible costs. Taking the latter classification, the direct cost component of EOD would include all the health related costs that are immediate consequences of discrimination. These costs include health sector costs such as outpatient costs, prescription drug purchases, medical fees etc. Other direct cost components include those borne by different sectors of an economy including production and consumption related costs, administrative, welfare/transfer and other costs.

Indirect costs involve productivity loss and other employment related costs associated with EOD. The loss in productivity includes, for instance, the costs incurred by employers due to absenteeism, resulting from the target having to cope with depression, physical illness, hospital visits etc. In addition, costs due to lower performance at work by employees exposed to discrimination are included. Potentially, however, the largest amount of illness cost due to EOD would come from the intangible cost component. In this paper, we estimate this aspect of the health cost of EOD. Intangible costs involve the pain, suffering and premature death associated with a risk factor/health outcome. For example, depression and related symptoms associated with EOD affect the wellbeing of targets. This and other associated illnesses can be included in the estimation of loss in wellbeing in terms of disability adjusted life years (DALYs), the tool widely used in costing a range of epidemiological conditions $[27,30]$. This tool allows us to determine the burden of disease (BoD) fractions of illnesses arising from the targets' exposures to discriminatory episodes.

\section{Methods \\ Data}

In this study, the individual target is the unit of reference. We use Australian self-report data from three nationally representative surveys (the Scanlon Foundation's Mapping Social Cohesion (MSC) survey, the Challenging Racism Project (CRP) and the 2012 National Dual-frame Omnibus Survey (DFO)) to estimate the prevalence of EOD. We utilise these prevalence data along with the magnitude of association between racism and four key health outcomes from a recent comprehensive meta-analysis [14] to calculate BoD estimates ascribed to EOD through loss of DALYs. We then use the results to compare the current health status with a counterfactual of no lifetime discrimination. Finally, we convert these estimates into monetary estimates using standard parameters. We then conduct sensitivity analysis for the robustness of the cost estimations, using three scenarios of the valuation of life (low, medium and high value of statistical life - VSL) and a range of discount rates. 


\section{Prevalence of EOD and its association with health}

Racial discrimination is usually measured either based on self-report or observational data [31]. One advantage of self-report data in discrimination research is that it enables researchers to directly measure the experiences of the targets [32-34]. Unlike observational data, it does not rely on observed differentials in the outcomes (e.g. wages and salaries, years of schooling etc.) of different racial groups per se to determine the prevalence of EOD. Self-report data can extract more complete data on EOD as perceived by targets themselves. However, self-report data can be susceptible to reporting bias [35]. Respondents may not correctly understand the question; they may over report their experiences (vigilance bias); or they may underreport them (minimisation bias). Yet, research to-date indicates that under- rather than over-reporting is more prevalent, in relation to racial discriminaton [36, 37]. Noting the strengths and drawbacks of self-report data, we utilise the three national surveys mentioned above to estimate EOD among Australian respondents.

\section{Measures \\ Prevalence of EOD in Australia}

Our first EOD measure is from the CRP survey $(n=12,512)$ which consists a series of surveys conducted between 2001 and 2008 in different states in Australia [38]. The EOD measure from this study has six items with 5-point Likert type responses where $22.3 \%$ of the respondents reported experiencing racial discrimination. The second dataset, the MSC survey ( $n=2000$ in each wave), was conducted between 2007 and 2013 [39]. A dichotomous EOD measure in this survey indicates that $9-19 \%$ of respondents reported EOD over the period 2007-13. The DFO survey (2012, $n=2000$ ), another Australian dataset conducted by the Social Research Centre, contains three items on racism as well as general health, physical activity, smoking, and substance use. Responses were coded $1=$ yes and $2=$ no, and almost $20 \%$ of the respondents indicated experiencing racial discrimination.

The prevalence data we utilise in this study classifies respondents first by gender, then by age into seven age categories, ranging 18-100 years. Table 1 below summarises the distribution of EOD in the three datasets based on age and gender. To generate a weighted average EOD data from the three national surveys, we first dichotomised the 5-point CRP EOD data, before decomposing the result by age and gender. EOD responses including "sometimes" and over were recoded as " 1 " while the rest were recoded as " 0 ". The last two columns of Table 1 indicate that the average prevalence of EOD among those aged 64 years and below ranged 13.4 to $20.1 \%$.

\section{Association between EOD and health outcomes}

A comprehensive assessment of the overall cost of EOD requires estimates of the health impact of exposure to EOD. As part of a recent meta-analysis, we investigated 293 studies, and found significant unadjusted associations between EOD and some key health outcomes, ranging from depression to hypertension, based on studies published until October 2013 [14]. Subject to our inclusion and exclusion criteria, we identified more than 21 associations of EOD and major health outcomes. ${ }^{1}$ However, in this study, we focus on only four illnesses across 102 studies, because the rest are either co-morbid with illnesses such as depression, or they are not available in the Global Burden of Disease which is the basis of our analysis. For example, chronic stress is associated with depression, and depression in turn is associated with obesity [40, 41].

In most cases, the studies we included utilise standard measures. For example, the instruments used in depression studies include the Centre for Epidemiological Studies Depression scale, the Major Depression Episodes, and the Beck Depression Inventory. For anxiety, studies utilised instruments such as the State Trait

Table 1 Prevalence of racial discrimination in Australia by age and gender

\begin{tabular}{|c|c|c|c|c|c|c|c|c|}
\hline \multirow[t]{3}{*}{ Age group } & \multicolumn{8}{|c|}{ Gender } \\
\hline & \multicolumn{2}{|l|}{ CRP } & \multicolumn{2}{|l|}{ MSC } & \multicolumn{2}{|l|}{ DFO } & \multicolumn{2}{|c|}{ Weighted average } \\
\hline & Males & Females & Males & Females & Males & Females & Males & Females \\
\hline $17-24$ & 32.7 & 24.8 & 20.0 & 14.6 & 18.8 & 23.5 & 23.8 & 20.1 \\
\hline $25-34$ & 33.6 & 21.8 & 16.5 & 13.4 & 25.7 & 32.5 & 22.3 & 19.0 \\
\hline $35-44$ & 28.5 & 21.8 & 13.2 & 12.9 & 22.7 & 23.7 & 18.5 & 18.0 \\
\hline $45-54$ & 26.6 & 19.9 & 12.7 & 11.6 & 13.8 & 23.4 & 17.0 & 16.5 \\
\hline $55-64$ & 24.8 & 15.6 & 7.9 & 9.7 & 17.4 & 20.1 & 13.7 & 13.4 \\
\hline $65-74$ & 14.8 & 10.7 & 5.2 & 5.7 & 10.0 & 16.8 & 8.4 & 9.0 \\
\hline $75-100$ & 9.7 & 7.2 & 5.1 & 0.6 & 4.7 & 13.3 & 6.4 & 4.8 \\
\hline
\end{tabular}

Note: Values are percentages of those who indicated they experienced racial discrimination in their lifetime. The last two columns are estimated based on the weighted average from CRP, MSC \& DFO data 
Anxiety Index, the Beck Anxiety Inventory and the General Health Questionnaire.

To allow an unbiased estimation of $\mathrm{BoD}$ attributable to EOD, the ideal effect size would be risk ratio (RR), indicating the prevalence rate of the health outcome among the exposed group relative to the unexposed group. However, almost all of the included studies (94.1\%) had insufficient data for the calculation of RR. Given sufficient data, it is possible to convert odds ratios (OR) to RR using the formula proposed by Zhang \& Yu [42]. However, the prevalence of the outcome on the control (unexposed) group was not reported for most of the studies reporting OR (and other OR convertible estimate). Therefore, only associations based on ORs $(n=197)$ were utilised in this paper, resulting in a focus on 101 studies (reported in 128 articles) involving 83,057 participants in total. There is a limitation in using $\mathrm{OR}$ in BoD analysis in that it exaggerates the risk of the outcome if the outcome of interest is common [43, 44]. However, Davies et al. [43] indicate that the size of the exaggeration depends on the size of the OR. Smaller OR would have minor exaggeration effect compared to large OR, therefore, using OR as alternative for $\mathrm{RR}$ would introduce minor exaggeration for $\mathrm{OR}<3.0$. In this study, the OR for all the illnesses except PTSD is less than three. Although we expect the OR for PTSD to have some exaggeration effect, the impact on the overall study findings is negligible given the small prevalence rate of PTSD considered here along with the small disability weight assigned to it in the GBD.

Within this association data, one issue that remained is the heterogeneity in the measures where the outcome scales varied from dichotomous (yes/no) categories to a range of categories including 3 to 9-point Likert type scales, and in some cases continuous measures. To account for this heterogeneity, we report two types of response categories. First, we report health outcomes for dichotomous response measure as one group with associations comparing the EOD-exposed and unexposed respondents. Second, we weight average the rest of the exposure measures and report them as one group comparing those who had low with those who had high level of EOD exposure (see Table 2). The sample size reported in Table 2 varies by the number of studies included, with depression having the largest overall sample $(n=124,049)$ and PTSD having the least overall sample $(n=2621)$. All associations were statistically significant (highly so in most cases) with odds ratios of two to three for all health outcomes except for PTSD.

\section{Statistical analysis \\ $D A L Y s$, PAF and health costs}

$\mathrm{BoD}$ analyses of risk factors/health outcomes are frequently used in measuring the health impact of a range of exposures. The health impact of EOD can likewise be estimated using this method. The World Health Organisation (WHO) provides guideline for the calculation of $\mathrm{BoD}$. Following this guideline, $\mathrm{BoD}$ can be defined as a measure quantifying 'the gap between a population's current health and an ideal situation where everyone lives to old age in full health' $[29$, p. 4]. It is numerically estimated in terms of DALYs where a loss of one DALY is equivalent to a loss of one healthy year of life [45]. Mathers et al. [46, p. 3] describe DALY as 'a summary measure of population health that combines in a single indicator, years of life lost from premature death and years of life lived with disabilities.' Several international studies have used BoD based on DALY in cost estimations for a range of illnesses [47-49].

Although BoD represents direct health impact resulting from the exposure, it is not a measure of immediate expenditures. It exists as an opportunity cost that was lost or a cost that can be averted. In different cost of illness studies, DALYs express the 'pain, suffering and premature

Table 2 List of association between EOD and health outcomes categorised by major illnesses

\begin{tabular}{|c|c|c|c|c|c|c|c|}
\hline \multirow[t]{2}{*}{ Illness/Health outcome } & \multicolumn{7}{|c|}{ Statistical outcome } \\
\hline & Odds ratio & Lower limit $(95 \% \mathrm{Cl})$ & Upper limit (95\% Cl) & Z-value & $P$-value & Total sample size & Number of associations \\
\hline \multicolumn{8}{|l|}{ A. Exposure response: yes/no } \\
\hline Anxiety & 2.050 & 1.758 & 2.391 & 9.140 & 0.000 & 13,216 & 13 \\
\hline Depression & 2.051 & 1.811 & 2.323 & 11.319 & 0.000 & 70,115 & 32 \\
\hline PTSD & 4.560 & 2.656 & 7.829 & 5.501 & 0.000 & 212 & 2 \\
\hline Psychological disorders & 2.584 & 2.068 & 3.137 & 9.318 & 0.000 & 13,705 & 3 \\
\hline \multicolumn{8}{|c|}{ B. Exposure response: 3-point and over } \\
\hline Anxiety & 2.275 & 1.619 & 3.279 & 4.922 & 0.019 & 11,228 & 37 \\
\hline Depression & 2.386 & 1.987 & 2.870 & 9.499 & 0.005 & 53,115 & 90 \\
\hline PTSD & 3.756 & 2.225 & 6.637 & 5.248 & 0.040 & 2021 & 9 \\
\hline Psychological disorders & 2.018 & 1.445 & 2.944 & 4.793 & 0.030 & 3946 & 11 \\
\hline
\end{tabular}

Note: This table reports the effect size of the association between EOD and health outcomes categorised by response types from a meta-analysis [14]. Panel A is based on a dichotomous measure of EOD while panel B is based on EOD measured as a categorical variable with 3-point and over response options 
mortality' component of the health costs. In this paper, prevalence data is used to estimate these costs attributable to racial discrimination. Either prevalence or incidence measures are used in the literature in the calculation of the BoD [45, 47]. Formally, DALY is calculated as:

$$
\begin{aligned}
D A L Y= & \text { Years of Life Lost } \\
& +\quad \text { Years Lived with Disability }
\end{aligned}
$$

where years of life lost is premature mortality due to exposure to the risk factor/illness and years lived with disability is the number of years of less than functional life attributable to the risk factor/illness. In theory, exposure to EOD is causally associated with some illnesses which are in turn causes of mortality (e.g., anxiety and depression, see: [47]). Due to the timing issue regarding the exposure to EOD and the incidence/prevalence of death, the causal relationship is likely to be confounded. In addition, mortality is already excluded from the meta-analysis which is the basis of our analysis, as racial discrimination per se appears to have no immediate association with mortality [50]. Therefore, assuming years of life lost $=0$ in this analysis, the measure to be estimated becomes:

$$
D A L Y=\text { Years Lived with Disability }
$$

where:

$$
Y L D=\text { Prevalence } * \text { Duration } * \text { Weight }
$$

where 'prevalence' is the prevalence of the illness, 'duration' refers to the duration of the illness since its onset, and 'weight' is the disability weight. To exploit the population attributable fraction (PAF), data already estimated in this paper, an alternative specification is used to estimate the DALYs [51]. The duration of illness is replaced by the PAF whereby the value will be interpreted as DALYs attributable to the EOD as a risk factor. This is specified by:

$$
D A L Y=\text { Prevalence } * \text { Weight } * P A F
$$

where PAF indicates the fraction measuring the degree of causal relationship between EOD and the illness. The PAF or BoD attributable to a risk factor (e.g., EOD) is estimated using the standard formula:

$$
P A F=\left[\sum_{i=0}^{k} p_{i}\left(R R_{i}-1\right)\right] \div\left[\sum_{i=0}^{k} p_{i}\left(R R_{i}-1\right)+1\right]
$$

where $i$ stands for the exposure category and $i=0$ represents the baseline category (no exposure); $p_{i}$ is the prevalence of the exposure (risk factor) for the $i$ th category; $R R_{i}$ is the relative risk for the group with $i$ level of exposure and is compared with no exposure. After some algebraic manipulation and assuming the relative risk for the unexposed group to be 1 , this formula can be rewritten as:

$$
P A F=\left[\sum_{c} p_{c} R R_{c}-1\right] \div\left[\sum_{c} p_{c} R R_{c}\right]
$$

where $c$ stands for the category of interest. Since most studies included for association estimation have no sufficient data to calculate relative risk (RR) ratio for an outcome, the formula we actually utilise in calculating the PAF is:

$$
P A F=\left[\sum_{c} p_{c} O R_{c}-1\right] \div\left[\sum_{c} p_{c} O R_{c}\right]
$$

Once we estimated the DALYs attributable to the prevalence of EOD, the next step is to convert them to monetary value which we do so using the value of statistical life (VSL) approach. A range of values have been suggested in the literature as conversion parameters [52-55]. These studies suggest a VSL value ranging between 0.6 million and $\$ 19.1$ million. A recent study by Andersson and Treich [56] reports a wider range of a VSL of \$261 thousand to \$36 million. The corresponding cost per DALY falls in the range of $\$ 70,000-\$ 175,000$. Drawing from the literature, Access Economics [57] uses a VSL of \$3.7-9.6 million in measuring the cost of domestic violence in Australia. This corresponds to a conversion rate of $\$ 162,561$ per DALY. In this analysis, we use a rate close to this $(\$ 166,250)$ as it draws from available evidence and best practice in an Australian context. The conversion involved key parameters including a VSL of $\$ 6.65$ million, a 3.3\% discount rate, and a timeframe of 40 years. Our conversion rate is estimated using the discounting formula:

$$
V S L=\sum \frac{\text { Value of Life Years }}{(1+r)^{t}}
$$

where $r$ is the discount rate. Value of life years is multiplied by DALY for each health outcome to convert the latter to a monetary value that represents the health cost attributable to the risk factor, an estimation we report in the next section.

\section{Results}

\section{Population attributable fractions}

The third stage of our analysis combines the prevalence measure of EOD and the corresponding association effect sizes we use to estimate population attributable fractions (PAFs). Tables 3 and 4 report the EOD related PAFs for males and females, for each of the illnesses which have statistically significant association with EOD. These tables report the proportion of the prevalence of the designated illness attributable to the prevalence of EOD. Table 3, which was calculated assuming no exposure to EOD, indicates that reducing EOD to zero can result in a $20 \%$ reduction in the prevalence of depression among men aged 
Table 3 Population attributable fractions: the prevalence of illness attributable to EOD (dichotomous) by age and gender

\begin{tabular}{|c|c|c|c|c|c|c|c|c|}
\hline \multirow[t]{3}{*}{ Age group } & \multicolumn{8}{|c|}{ Illness/Health outcome } \\
\hline & \multicolumn{2}{|c|}{ Depression } & \multicolumn{2}{|l|}{ Anxiety } & \multicolumn{2}{|l|}{ PTSD } & \multicolumn{2}{|c|}{ Psychological disorders } \\
\hline & PAF (\%) & $95 \% \mathrm{Cl}$ & PAF (\%) & $95 \% \mathrm{Cl}$ & PAF (\%) & $95 \% \mathrm{Cl}$ & PAF (\%) & $95 \% \mathrm{Cl}$ \\
\hline \multicolumn{9}{|l|}{ Males } \\
\hline $17-24$ & 20 & $(16.2-23.9)$ & 20 & $(15.3-24.9)$ & 45.9 & $(28.3-61.9)$ & 27.4 & $(20.3-33.7)$ \\
\hline $25-34$ & 19 & $(15.3-22.8)$ & 19 & $(14.4-23.7)$ & 44.2 & $(26.9-60.3)$ & 26.1 & $(19.2-32.2)$ \\
\hline $35-44$ & 16.2 & $(13.0-19.6)$ & 16.2 & $(12.3-20.4)$ & 39.6 & $(23.4-55.8)$ & 22.6 & $(16.5-28.3)$ \\
\hline $45-54$ & 15.2 & $(12.1-18.4)$ & 15.1 & $(11.4-19.1)$ & 37.7 & $(22.0-53.7)$ & 21.2 & $(15.4-26.6)$ \\
\hline $55-64$ & 12.6 & $(10.0-15.3)$ & 12.6 & $(9.4-16.0)$ & 32.7 & $(18.5-48.3)$ & 17.8 & $(12.7-22.6)$ \\
\hline $65-74$ & 8.1 & $(6.4-10.0)$ & 8.1 & $(6.0-10.5)$ & 23 & $(12.2-36.5)$ & 11.8 & $(8.2-15.2)$ \\
\hline $75-100$ & 6.3 & $(5.0-7.9)$ & 6.3 & $(4.7-8.2)$ & 18.7 & $(9.6-30.6)$ & 9.3 & $(6.4-12.1)$ \\
\hline \multicolumn{9}{|l|}{ Females } \\
\hline $17-24$ & 17.4 & $(14.0-21.0)$ & 17.4 & $(13.2-21.8)$ & 41.7 & $(25.0-57.8)$ & 24.1 & $(17.7-30.0)$ \\
\hline $25-34$ & 16.6 & $(13.3-20.1)$ & 16.6 & $(12.6-20.9)$ & 40.3 & $(23.9-56.4)$ & 23.1 & $(16.8-28.8)$ \\
\hline $35-44$ & 15.9 & $(12.7-19.2)$ & 15.9 & $(12.0-20.0)$ & 39 & $(22.9-55.1)$ & 22.2 & $(16.1-27.7)$ \\
\hline $45-54$ & 14.8 & $(11.8-17.9)$ & 14.8 & $(11.1-18.6)$ & 37 & $(21.4-53.0)$ & 20.7 & $(15.0-26.0)$ \\
\hline $55-64$ & 12.3 & $(9.8-15)$ & 12.3 & $(9.2-15.7)$ & 32.3 & $(18.1-47.7)$ & 17.5 & $(12.5-22.2)$ \\
\hline $65-74$ & 8.7 & $(6.8-10.7)$ & 8.6 & $(6.4-11.1)$ & 24.3 & $(13.0-38.1)$ & 12.5 & $(8.8-16.1)$ \\
\hline 75-100 & 4.8 & $(3.7-5.9)$ & 4.8 & $(3.5-6.2)$ & 14.5 & $(7.3-24.6)$ & 7 & $(4.9-9.3)$ \\
\hline
\end{tabular}

Note: All PAF values are percentages indicating the proportion of each illness attributable to exposure to racial discrimination and were calculated based on the prevalence data discussed in the text. Values in parenthesis are confidence intervals

Table 4 Population attributable fractions: the prevalence of illness attributable to EOD (non-dichotomous) by age and gender

\begin{tabular}{|c|c|c|c|c|c|c|c|c|}
\hline \multirow[t]{3}{*}{ Age group } & \multicolumn{8}{|c|}{ Illness/Health outcome } \\
\hline & \multicolumn{2}{|c|}{ Depression } & \multicolumn{2}{|l|}{ Anxiety } & \multicolumn{2}{|l|}{ PTSD } & \multicolumn{2}{|c|}{ Psychological disorders } \\
\hline & PAF (\%) & $95 \% \mathrm{Cl}$ & PAF (\%) & $95 \% \mathrm{Cl}$ & PAF (\%) & $95 \% \mathrm{Cl}$ & PAF (\%) & $95 \% \mathrm{Cl}$ \\
\hline \multicolumn{9}{|l|}{ Males } \\
\hline $17-24$ & 27.8 & $(15.4-40.7)$ & 24.8 & $(19.0-30.8)$ & 29.5 & $(20.2-39.3)$ & 23.4 & $(13.2-36.4)$ \\
\hline $25-34$ & 26.5 & $(14.6-39.2)$ & 23.6 & $(18.0-29.4)$ & 28.1 & $(19.2-37.7)$ & 22.3 & $(12.5-34.9)$ \\
\hline $35-44$ & 23 & $(12.4-34.8)$ & 20.4 & $(15.4-25.7)$ & 24.5 & $(16.5-33.4)$ & 19.2 & $(10.6-30.7)$ \\
\hline $45-54$ & 21.5 & $(11.5-32.9)$ & 19.1 & $(14.4-24.1)$ & 23 & $(15.4-31.6)$ & 17.9 & $(9.8-29.0)$ \\
\hline $55-64$ & 18.1 & $(9.5-28.3)$ & 15.9 & $(11.9-20.4)$ & 19.4 & $(12.7-27.1)$ & 15 & $(8.1-24.7)$ \\
\hline $65-74$ & 12 & $(6.1-19.6)$ & 10.4 & $(7.7-13.6)$ & 12.9 & $(8.2-18.6)$ & 9.8 & $(5.1-16.8)$ \\
\hline $75-100$ & 9.4 & $(4.7-15.7)$ & 8.2 & $(6.0-10.8)$ & 10.2 & $(6.4-14.9)$ & 7.7 & $(4.0-13.4)$ \\
\hline \multicolumn{9}{|l|}{ Females } \\
\hline $17-24$ & 24.5 & $(13.4-36.7)$ & 21.8 & $(16.6-27.3)$ & 26.1 & $(17.7-35.4)$ & 20.5 & $(11.4-32.6)$ \\
\hline $25-34$ & 23.5 & $(12.7-35.4)$ & 20.8 & $(15.8-26.2)$ & 25 & $(16.8-34.0)$ & 19.6 & $(10.8-31.3)$ \\
\hline $35-44$ & 22.5 & $(12.1-34.2)$ & 19.9 & $(15.1-25.1)$ & 24 & $(16.1-32.8)$ & 18.8 & $(10.3-30.2)$ \\
\hline $45-54$ & 21 & $(11.2-32.3)$ & 18.6 & $(14.0-23.6)$ & 22.4 & $(15.0-31.0)$ & 17.5 & $(9.6-28.4)$ \\
\hline $55-64$ & 17.8 & $(9.3-27.9)$ & 15.6 & $(11.7-20.0)$ & 19 & $(12.5-26.7)$ & 14.7 & (7.9-24.3) \\
\hline $65-74$ & 12.7 & $(6.5-20.7)$ & 11.1 & $(8.2-14.4)$ & 13.7 & $(8.8-19.7)$ & 10.4 & $(5.5-17.8)$ \\
\hline $75-100$ & 7.2 & $(3.5-12.1)$ & 6.2 & $(4.5-8.2)$ & 7.7 & $(4.9-11.5)$ & 5.8 & $(3.0-10.3)$ \\
\hline
\end{tabular}


17-24. A similar reduction of EOD can result in an 18.7\% reduction in the prevalence of stress among women aged $35-44$. The rest of the values can be interpreted likewise.

Tables 4 is the non-dichotomous (3-point and above) exposure measure version of Tables 3 , reporting the proportion of the prevalence of the designated illness attributable to the prevalence of EOD among men and women respectively. The values are calculated assuming EOD can be reduced from high to the lowest theoretical minimum. For example, reducing EOD to the lowest possible level can result in a $23.6 \%$ reduction in the prevalence of anxiety among men aged 25-34. A similar reduction of EOD can result in a $22.4 \%$ reduction in the prevalence of PTSD among women aged 45-54. Likewise, a reduction of EOD to its theoretical minimum, would reduce the prevalence of depression among men aged $25-34$ years by $26.5 \%$. This would mean a $26.5 \%$ saving in the treatment cost of depression in this age group. The rest of the values can be interpreted similarly.

\section{Disability Adjusted Life Years (DALYs)}

Table 5 reports the final results of our BoD analysis. A total of 235,452 DALYs per year is lost in Australia which can be attributed to the prevalence of EOD. The number of DALYs lost is relatively higher among women $(\mathrm{DALY}=140,073$ ) compared to men (DALY $=95,397$ ). Depression for women (32.0\%) and psychological disorders for men (33.8\%) are the leading causes. For men, depression accounts for 30.3\% of lost DALYs attributable to EOD. Overall, the loss in DALYs caused by EOD is estimated to be $8.9 \%$ of DALYs from all causes in Australia. This would place EOD above tobacco as a major risk factor since tobacco was estimated to account for 204,788 in lost DALYs (according to the 2003 BoD in Australia, see [47]). A detailed version of this table which disaggregates the findings by age groups is reported in Tables 8 and 9 in Appendix.

Table 5 EOD attributable burden of disease (DALYs) by gender and causes in Australia

\begin{tabular}{llll}
\hline Cause/IIness & Male (\%) & Female (\%) & Total \\
\hline Anxiety & $15,890(16.7)$ & $24,908(17.8)$ & 40,797 \\
Depression & $28,888(30.3)$ & $44,786(32.0)$ & 73,673 \\
PTSD & $18,366(19.3)$ & $32,776(23.4)$ & 51,142 \\
Psychological disorders & $32,235(33.8)$ & $37,604(26.8)$ & 69,840 \\
$\begin{array}{l}\text { Total of illnesses attributable } \\
\text { to EOD }\end{array}$ & $95,379(100)$ & $140,073(100)$ & 235,452 \\
$\begin{array}{l}\text { DALYs from all causes in } \\
\text { Australia }\end{array}$ & $1,364,614$ & $1,268,156$ & $2,632,770$ \\
$\begin{array}{l}\text { Percentage of all DALYs } \\
\text { attributable to EOD }\end{array}$ & $7.0 \%$ & $11.0 \%$ & $8.9 \%$ \\
\hline
\end{tabular}

Note: The values are DALYs attributable to the prevalence of EOD in a year. The percentages in parentheses indicate DALYs caused by EOD as a proportion of the total

${ }^{a}$ This data was taken from The burden of disease and injury in Australia 2003 [49]

\section{The health costs of racial discrimination}

The monetary estimate of the total DALYs attributable to EOD allows for comparison with aggregate economic measures. Table 6 reports the health cost of EOD in Australia, calculated using the value of statistical life (VSL) approach. According to this estimation, EOD accounts for a total of $\$ 37.9$ billion in health cost to the Australian economy. This is roughly $3.02 \%$ of the annual average GDP for the period 2001-11 (for GDP figures see [58]). The largest cost of EOD, \$11.9 billion, comes through its effect on depression. This result is comparable with previous studies which used a human capital approach to estimate the cost of EOD. Particularly, the Joint Economic Committee has reported that EOD costed the U.S. economy 4\% of GDP while Brimmer [24] estimated the EOD cost to be $\$ 241$ billion (3.8\% GDP).

\section{Sensitivity analysis}

To check the robustness of the costs reported in Table 6, we have conducted a sensitivity analysis. We look at three scenarios where we use three VSL values: \$3.7 million, $\$ 6.65$ million and $\$ 9.6$ million. For each of these VSL values, we varied the underlying discount rates in the 0 $10 \%$ range. The result, reported in Table 7 , indicates a range of health costs due to EOD. At the lower VSL scenario (Panel A) the overall cost of EOD ranges between 1.6 and $1.7 \%$ of the average GDP for Australia for the 2001-11 periods. Using the highest discount rate of $10 \%$ yields an EOD cost of $\$ 19.8$ billion while a $0 \%$ discount rate results in $\$ 21.8$ billion. At a $3.3 \%$ discount rate the estimated cost is $\$ 21.1$ billion or $1.7 \%$ of GDP.

At the medium VSL value of $\$ 6.65$ million (Panel B), the health cost of EOD ranges between 2.9 and $3.1 \%$ of average annual GDP (2001-11) [59]. This is $\$ 33$ billion at a discount rate of $10 \%$ and $\$ 39.1$ billion at $0 \%$ discount rate, for the discount rate of $3.3 \%$ the cost is $\$ 37.9$ billion or $3 \%$ of GDP. Similarly, at a high VSL of $\$ 9.6$ billion (Panel C), the cost is $4.1-4.5 \%$ of GDP or $\$ 51.4$ billion for $10 \%$ discount rate and $\$ 56.5$ billion for $0 \%$ discount rate. At a 3.3\%

\begin{tabular}{llll}
\multicolumn{4}{l}{ Table 6 Health cost of racial discrimination in Australia (\$ millions) } \\
\hline Cause/lllness & Men & Women & Total cost \\
\hline Anxiety & 2557 & 4009 & 6566 \\
Depression & 4649 & 7208 & 11,857 \\
PTSD & 2956 & 5275 & 8231 \\
$\begin{array}{l}\text { Psychological disorders } \\
\text { a }\end{array}$ & 5188 & 6052 & 11,240 \\
$\begin{array}{l}\text { Total of illnesses attributable } \\
\text { to EOD }\end{array}$ & 15,350 & 22,543 & 37,893 \\
$\begin{array}{l}\text { Australian average annual } \\
\text { GDP (2001-2011) }\end{array}$ & & & \\
$\begin{array}{l}\text { Health cost of EOD as a percentage } \\
\text { of GDP }\end{array}$ & & & $1,256,769$ \\
\hline
\end{tabular}

Source (for GDP data): World Bank national accounts data, and OECD National Accounts data files. GDP is in constant local currency unit (LCU)

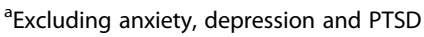


Table 7 Sensitivity analysis: health cost of racial discrimination in Australia (\$ millions)

\begin{tabular}{|c|c|c|c|c|c|c|c|c|c|c|c|c|c|}
\hline \multirow[t]{2}{*}{ Cause of Illness } & \multirow[t]{2}{*}{ DALYS } & \multicolumn{12}{|c|}{ Discount rate } \\
\hline & & $0 \%$ & $1 \%$ & $2 \%$ & $3 \%$ & $3.3 \%$ & $4 \%$ & $5 \%$ & $6 \%$ & $7 \%$ & $8 \%$ & $9 \%$ & $10 \%$ \\
\hline \multicolumn{14}{|l|}{ Scenario A: VSL $=\$ 3.7$ million } \\
\hline Anxiety & 40,797 & 3774 & 3736 & 3700 & 3664 & 3653 & 3629 & 3594 & 3560 & 3527 & 3494 & 3462 & 3431 \\
\hline Depression & 73,673 & 6815 & 6747 & 6681 & 6616 & 6597 & 6553 & 6490 & 6429 & 6369 & 6310 & 6252 & 6195 \\
\hline PTSD & 51,142 & 4731 & 4684 & 4638 & 4593 & 4579 & 4549 & 4505 & 4463 & 4421 & 4380 & 4340 & 4301 \\
\hline Psychological disorders ${ }^{\mathrm{a}}$ & 69,840 & 6460 & 6396 & 6333 & 6272 & 6254 & 6212 & 6153 & 6094 & 6038 & 5982 & 5927 & 5873 \\
\hline Total of illnesses attributable to EOD & 235,452 & 21,779 & 21,564 & 21,352 & 21,145 & 21,084 & 20,942 & 20,742 & 20,547 & 20,354 & 20,166 & 19,981 & 19,799 \\
\hline Australian average annual GDP (2005-2012) & & $1,256,769$ & $1,256,769$ & $1,256,769$ & $1,256,769$ & $1,256,769$ & $1,256,769$ & $1,256,769$ & $1,256,769$ & $1,256,769$ & $1,256,769$ & $1,256,769$ & $1,256,769$ \\
\hline Health cost of EOD as a percentage of GDP & & $1.7 \%$ & $1.7 \%$ & $1.7 \%$ & $1.7 \%$ & $1.7 \%$ & $1.7 \%$ & $1.7 \%$ & $1.6 \%$ & $1.6 \%$ & $1.6 \%$ & $1.6 \%$ & $1.6 \%$ \\
\hline \multicolumn{14}{|l|}{ Scenario B: VSL $=\$ 6.65$ million } \\
\hline Anxiety & 40,797 & 6783 & 6715 & 6650 & 6585 & 6566 & 6522 & 6460 & 6399 & 6339 & 6280 & 6222 & 6166 \\
\hline Depression & 73,673 & 12,248 & 12,127 & 12,008 & 11,891 & 11,857 & 11,777 & 11,665 & 11,555 & 11,447 & 11,341 & 11,237 & 11,135 \\
\hline PTSD & 51,142 & 8502 & 8418 & 8336 & 8255 & 8231 & 8175 & 8097 & 8021 & 7946 & 7873 & 7800 & 7729 \\
\hline Psychological disorders ${ }^{\mathrm{a}}$ & 69,840 & 11,611 & 11,496 & 11,383 & 11,273 & 11,240 & 11,164 & 11,058 & 10,954 & 10,851 & 10,751 & 10,652 & 10,555 \\
\hline Total of illnesses attributable to EOD & 235,452 & 39,144 & 38,756 & 38,376 & 38,004 & 37,893 & 37,638 & 37,280 & 36,928 & 36,583 & 36,244 & 35,912 & 32,960 \\
\hline Australian average annual GDP (2005-2012) & & $1,256,769$ & $1,256,769$ & $1,256,769$ & $1,256,769$ & $1,256,769$ & $1,256,769$ & $1,256,769$ & $1,256,769$ & $1,256,769$ & $1,256,769$ & $1,256,769$ & $1,256,769$ \\
\hline Health cost of EOD as a percentage of GDP & & $3.1 \%$ & $3.1 \%$ & $3.1 \%$ & $3.0 \%$ & $3.0 \%$ & $3.0 \%$ & $3.0 \%$ & $2.9 \%$ & $2.9 \%$ & $2.9 \%$ & $2.9 \%$ & $2.9 \%$ \\
\hline \multicolumn{14}{|l|}{ Scenario B: VSL $=\$ 9.6$ million } \\
\hline Anxiety & 40,797 & 9791 & 9694 & 9599 & 9506 & 9479 & 9415 & 9325 & 9237 & 9151 & 9066 & 8983 & 8901 \\
\hline Depression & 73,673 & 17,682 & 17,507 & 17,335 & 17,167 & 17,117 & 17,002 & 16,840 & 16,681 & 16,525 & 16,372 & 16,222 & 16,074 \\
\hline PTSD & 51,142 & 12,274 & 12,152 & 12,033 & 11,917 & 11,882 & 11,802 & 11,690 & 11,579 & 11,471 & 11,365 & 11,261 & 11,158 \\
\hline Psychological disorders ${ }^{\mathrm{a}}$ & 69,840 & 16,762 & 16,596 & 16,433 & 16,273 & 16,226 & 16,117 & 15,963 & 15,813 & 15,665 & 15,520 & 15,378 & 15,238 \\
\hline Total of illnesses attributable to EOD & 235,452 & 56,508 & 55,949 & 55,400 & 54,863 & 54,703 & 54,335 & 53,818 & 53,310 & 52,812 & 52,323 & 51,843 & 51,371 \\
\hline Australian average annual GDP (2005-2012) & & $1,256,769$ & $1,256,769$ & $1,256,769$ & $1,256,769$ & $1,256,769$ & $1,256,769$ & $1,256,769$ & $1,256,769$ & $1,256,769$ & $1,256,769$ & $1,256,769$ & $1,256,769$ \\
\hline Health cost of EOD as a percentage of GDP & & $4.5 \%$ & $4.5 \%$ & $4.4 \%$ & $4.4 \%$ & $4.4 \%$ & $4.3 \%$ & $4.3 \%$ & $4.2 \%$ & $4.2 \%$ & $4.2 \%$ & $4.1 \%$ & $4.1 \%$ \\
\hline
\end{tabular}

Note: This table is a sensitivity analysis of the results reported in Table 6 at a range of discount rates for three scenarios: Panel A assuming a value of statistical life of $\$ 3.7$ million, Panel B $\$ 6.65$ million, and Panel C $\$ 9.6$ million. The benchmark discount rate and the associated values are indicated in bold numbers. Values reported in columns 1-11 are in millions of dollars unless indicated otherwise aExcluding anxiety, depression and PTSD 
discount rate, EOD costs $4.4 \%$ of GDP, or $\$ 54.7$ billion per annum.

It can be concluded that the cost estimation varies depending on the underlying parameters, discount rate and VSL estimates. Using the same discount rate (3.3\%), the cost estimate variation across VSL estimates is in the range of $\$ 21.1-\$ 54.7$ billion (1.7-4.4\% of GDP).

\section{Discussion}

In this study, we estimated the economic value of reducing EOD directly from an estimated BoD data. Using a cost of illness method, we measured the PAFs for four key health outcomes (depression, anxiety, PTSD and psychological disorders). Our findings indicate substantial loss in DALYs due to EOD. On the average, Australia loses up to $3.02 \%$ of GDP per annum as a result of individuals being exposed to some form of racial discrimination. Gender differences are evident in the DALYs estimated due to the prevalence of both racial discrimination and the illnesses. Empirical evidence shows that the prevalence of psychological illnesses tends to be higher among women than men [58,60]. In addition, the prevalence of EOD also tends to be higher among women $[59,61,62]$, as is evidenced in our data. This corresponded with higher prevalence of mental illnesses, leading to higher values of estimated DALYs.

The cost of illnesses estimates reported in this study reflect cost savings measured against their counterfactuals. They can potentially be realised via measures that can reduce the prevalence of racial discrimination, as a risk factor, to zero or the possible minimum. However, the findings we report should be considered exploratory and indicative. They do not necessarily represent immediately realisable estimates. They are opportunity costs, costs that could be saved by avoiding the need for treating the preventable disease [63]. A range of assumptions are involved in this estimation, the causality of the relationship between EOD exposure and health being the most important.

First, establishing causal relationship between EOD and health outcomes from cross-sectional studies has limitations as a target could be experiencing negative health outcomes due to multiple factors. Reverse causation between EOD and negative health outcomes cannot be ruled out although there is considerable evidence suggesting that EOD precedes ill-health [14, 64]. Obtaining association data in terms of RR rather than OR should improve the accuracy of the findings and solve the causality issue. Second, only unadjusted associations between EOD and health are utilised in this analysis. However, confounding due to multivariate effects in such associations cannot be ruled out. For example, factors such as demographic and socio-economic factors can also have a role in EOD and health outcomes. A thorough investigation of longitudinal analysis and adjusted associations should, therefore, give a better picture regarding the $\mathrm{BoD}$ outcomes related to the EOD.
Our estimation of DALYs also has some limitations. First, our study has estimated the cost of EOD for only four illnesses although the literature indicates association with physical illnesses such as hypertension, diabetes and hypercholesterolemia [65]. This is likely to lead to the underestimation of the health cost estimates reported. The main reason for the exclusion of physical illnesses in this study is insufficient data for the calculation of BoD estimates. Apart from the four illnesses indicated in Table 5, we could not use 21 associations we analysed in a meta-analysis for they are not available in the Global Burden of Disease (GBD). Either they are only risk factors which cannot be strictly considered illnesses (e.g., overweight, obesity etc.) or they are not defined in the GBD due to co-morbidity (e.g., stress, psychological distress, internalizing symptoms etc.). For those which are not in the GBD categories no disability weight data is available for the calculation of DALYs. For mental/psychological disorder, a composite disability weight index was used by averaging across all the mental disorders weights available in the GBD, Vos \& Mathers [66] and Begg et al. [47].

Second, we could not find prevalence data for some illnesses (e.g., stress, internalizing symptoms etc.). Therefore, the requirement for the calculation of DALYs could be completed for just four studies. The association data was obtained from our recent meta-analysis of studies [14] conducted at various times with prevalence data for the period 2001-11. Therefore, there may be confounding across different time periods. The DALYs are crudely measured without accounting for time lag, and adjustments for any confounders. Further refinement and the inclusion of relevant associations are needed to give definitive conclusion regarding the DALYs caused by EOD.

Furthermore, the data used in the calculation are heterogeneous. Prevalence data for anxiety and psychological disorder was obtained from the National Survey of Mental Health and Wellbeing [67]. For depression and PTSD, the prevalence rate from the same source is aggregated by gender. This was disaggregated across age groups using census data, based on the information that depression has similar variation across age groups up to 64 and declining thereafter for those aged 65 and over [68]. In addition, disability weights were obtained from a range of studies including the GBD [69], Vos \& Mathers [66], the 2005 Victorian Burden of Disease Study, and Begg et al. [47]. The derivation of these weights, particularly for psychological disorders, involved averaging across studies and disease categories. For example, the GBD [69] disaggregates the weights by age group; Vos \& Mathers [66] provide weight range while a single weight is used in the Victorian BoD.

Our estimation does not include direct healthcare expenditures and indirect costs associated with racial discrimination which can arise from inefficiency in the labour market due to the underutilisation of education, skills and 
experiences of the targets. As such, even for the few health outcomes for which there was the requisite data, our estimates are lower bound as they only measure intangible costs.

Therefore, the total cost is likely to be higher than 3.02\% if all cost components were included. A fuller costing of EOD would include hospitalisation and out-of-pocket expenses in addition to the BoD-based intangible cost reported in Table 6. According to the AIHW, Australians (individuals), on the average covered $17.3 \%$ of the total health expenditure in 2000-2012 [70]. The rest of the health cost was funded by state and federal governments and private insurers. The AIHW [71] reports that out of pocket expenses accounted for $18.2 \%$ of total health spending, and averaged at 2.4 to $2.8 \%$ of total household spending in the decade ending 2009. 'More than half of nongovernment funding (58\%) came from out-of-pocket payments by individuals. This included circumstances where individuals met the full cost of goods or services, as well as where they shared the cost, for example, with private health insurance funds or the Australian Government through Medicare' (p.475). According to this report, the total outof-pocket spending by individuals covered $\$ 7.7$ billion or $47 \%$ of the total cost of medications in the years 2009-10. Addition of such costs attributable to EOD exposure can therefore substantially increase the health cost of EOD. ${ }^{2}$

Finally, this study focused on Australian data. However, the analysis can be replicated cross-nationally with potentially comparable findings. The exact cost of EOD for each country will depend on the prevalence rate of EOD, with countries that exhibit higher EOD prevalence also bearing higher overall cost.

\section{Conclusion}

We measured the economic impact of EOD in Australia from the societal perspective. Economic costs are usually estimated based on production loss and/or the consumption of resources. Another important cost component is the pain and suffering involved due to illness that can be attributed to a risk factor, such as racial discrimination. In this study, we found the BoD attributable to EOD associated with anxiety, depression, PTSD and psychological disorders to be substantial. Overall, the four illnesses accounted for 235,452 DALYs lost in Australia due to EOD of which depression accounted for $31.3 \%$ of the total DALYs.

In monetary terms, for a VSL of $\$ 6.65$ million, a time period of 40 years and a discount rate of $3.3 \%$, which is roughly $\$ 166,250$ per DALY, we estimated the cost of EOD related to the four health outcomes to be $\$ 37.9$ billion, which is roughly $3.02 \%$ of the average annual GDP (2001-2011) of Australia [72]. This is proportional to previous findings in U.S. studies that are based on the human capital approach.
Using new evidence and integrating it with advances in public health research, our study was able to estimate the economy-wide loss directly attributable to EOD. The evidence clearly shows that the Australian economy would be significantly better off in the absence of EOD. In addition to its infringement on the rights of individuals and groups, racial discrimination has detrimental impact on the economy. The cost would even be much higher if discrimination related direct expenditures were added. As such, the addition of hospitalisation and out-of-pocket expenditure should also be estimated in future work to give a better picture of the total health cost of EOD. The other source of cost is the indirect costs related to loss of productivity. As there exists little research that has estimated this, more research is needed in this area to corroborate the scant evidence base regarding the cost of EOD.

In summary, although we did not include a range of cost items in our analysis, our study was able to estimate a vital aspect of the cost of racial discrimination. We found that racial discrimination is substantially costly to the health of individuals expressed in loss of healthy life years. The findings of this study are particularly important in informing public policies and advocacy activities related to public health, community social cohesion, anti-discrimination and cultural diversity. By quantifying the cost of discrimination, the study contributes to the rationale for antiracism strategies that seek to benefit society by reducing the costs associated with discrimination. The findings also indicate that given some of the costs resulting from EOD are avoidable, measures taken by governmental and nongovernmental institutions to curb racial discrimination are likely to be socially and economically feasible. Countries with racially and ethnically diverse population can therefore realise substantial savings by enforcing effective antidiscrimination measures [73].

\section{Endnotes}

${ }^{1}$ The inclusion criteria which can be found in Paradies et al. [14] include:

1. be published in a journal article or dissertation

2. report at least one association between racism and a health outcome/s

3. be an empirical study

4. report quantitative data

5. contain relevant exposure/s and/or outcome/s

6. report unadjusted associations

7. report statistics that allow calculation of effect size

For this paper, further inclusion criteria were added:

1. The study has to report at least one of four health outcomes (depression, anxiety, PTSD and psychological disorder).

2. It has to report statistics/data that allow for the calculation of OR. 
${ }^{2}$ Another source of cost would be litigation cost that results if alleged racial discrimination is brought to the court. Some of the settlement and litigation cost would be transfer payment and may not be attributed as loss in GDP. But, some part would be incurred as a loss to society as time and resources are diverted to execute the litigation process. An example for this is the $\$ 72.69$ million per annum lost in litigation cost to settle racial discrimination complaints in the U.S. (see: a 2014 Equal Employment Opportunity Commission report).

\section{Appendix}

Table 8 EOD attributable burden of disease (DALYs) for men in Australia by age and causes

\begin{tabular}{|c|c|c|c|c|c|}
\hline $\begin{array}{l}\text { Type of Illness/ } \\
\text { Health outcome }\end{array}$ & $\begin{array}{l}\text { Age } \\
\text { category }\end{array}$ & $\begin{array}{l}\text { Prevalent } \\
\text { cases }\end{array}$ & $\begin{array}{l}\text { Disability } \\
\text { weight }\end{array}$ & PAF & DALYS \\
\hline \multirow[t]{7}{*}{ Anxiety } & $17-24$ & 92,660 & 0.149 & 0.200 & 2759 \\
\hline & $25-34$ & 125,395 & 0.149 & 0.190 & 3542 \\
\hline & $35-44$ & 176,308 & 0.149 & 0.162 & 4264 \\
\hline & $45-54$ & 150,582 & 0.149 & 0.151 & 3398 \\
\hline & $55-64$ & 79,335 & 0.149 & 0.126 & 1484 \\
\hline & $65-74$ & 30,116 & 0.149 & 0.081 & 364 \\
\hline & 75-100 & 8473 & 0.149 & 0.063 & 80 \\
\hline \multirow[t]{7}{*}{ Depression } & $17-24$ & 90,907 & 0.283 & 0.200 & 5145 \\
\hline & $25-34$ & 125,465 & 0.283 & 0.190 & 6735 \\
\hline & $35-44$ & 131,571 & 0.283 & 0.162 & 6048 \\
\hline & $45-54$ & 123,803 & 0.283 & 0.152 & 5310 \\
\hline & $55-64$ & 99,971 & 0.283 & 0.126 & 3554 \\
\hline & $65-74$ & 61,090 & 0.283 & 0.081 & 1404 \\
\hline & 75-100 & 38,529 & 0.283 & 0.063 & 692 \\
\hline \multirow[t]{7}{*}{ PTSD } & $17-24$ & 69,178 & 0.096 & 0.459 & 3045 \\
\hline & $25-34$ & 95,475 & 0.096 & 0.442 & 4054 \\
\hline & $35-44$ & 100,122 & 0.096 & 0.396 & 3811 \\
\hline & $45-54$ & 94,210 & 0.096 & 0.377 & 3410 \\
\hline & $55-64$ & 76,075 & 0.096 & 0.327 & 2391 \\
\hline & $65-74$ & 46,488 & 0.096 & 0.23 & 1028 \\
\hline & 75-100 & 35,090 & 0.096 & 0.187 & 629 \\
\hline \multirow{7}{*}{$\begin{array}{l}\text { Psychological } \\
\text { disorders }\end{array}$} & $17-24$ & 296,300 & 0.224 & 0.125 & 8289 \\
\hline & $25-34$ & 321,500 & 0.224 & 0.118 & 8490 \\
\hline & $35-44$ & 319,000 & 0.224 & 0.100 & 7122 \\
\hline & $45-54$ & 262,100 & 0.224 & 0.093 & 5433 \\
\hline & $55-64$ & 126,500 & 0.224 & 0.076 & 2148 \\
\hline & $65-74$ & 53,800 & 0.224 & 0.048 & 579 \\
\hline & 75-100 & 20,900 & 0.224 & 0.037 & 174 \\
\hline Total & & & & & 95,379 \\
\hline
\end{tabular}

Note: DALYs are estimated using the standard formula (3) for each illness by age group
Table 9 EOD attributable burden of disease (DALYs) for women in Australia by age and causes

\begin{tabular}{|c|c|c|c|c|c|}
\hline $\begin{array}{l}\text { Type of Illness/ } \\
\text { Health outcome }\end{array}$ & $\begin{array}{l}\text { Age } \\
\text { category }\end{array}$ & $\begin{array}{l}\text { Prevalent } \\
\text { cases }\end{array}$ & $\begin{array}{l}\text { Disability } \\
\text { weight }\end{array}$ & PAF & DALYS \\
\hline \multirow[t]{7}{*}{ Anxiety } & $17-24$ & 206,467 & 0.149 & 0.174 & 5359 \\
\hline & $25-34$ & 226,359 & 0.149 & 0.166 & 5600 \\
\hline & $35-44$ & 248,614 & 0.149 & 0.159 & 5878 \\
\hline & $45-54$ & 235,276 & 0.149 & 0.148 & 5171 \\
\hline & $55-64$ & 122,097 & 0.149 & 0.123 & 2241 \\
\hline & $65-74$ & 39,403 & 0.149 & 0.086 & 508 \\
\hline & 75-100 & 21,035 & 0.149 & 0.048 & 150 \\
\hline \multirow[t]{7}{*}{ Depression } & $17-24$ & 143,311 & 0.283 & 0.174 & 7071 \\
\hline & $25-34$ & 205,822 & 0.283 & 0.166 & 9680 \\
\hline & $35-44$ & 220,309 & 0.283 & 0.159 & 9902 \\
\hline & $45-54$ & 207,824 & 0.283 & 0.148 & 8683 \\
\hline & $55-64$ & 165,160 & 0.283 & 0.123 & 5761 \\
\hline & $65-74$ & 105,170 & 0.283 & 0.087 & 2575 \\
\hline & 75-100 & 82,283 & 0.283 & 0.048 & 1113 \\
\hline \multirow[t]{7}{*}{ PTSD } & $17-24$ & 122,265 & 0.096 & 0.417 & 4895 \\
\hline & $25-34$ & 175,596 & 0.096 & 0.403 & 6794 \\
\hline & $35-44$ & 187,956 & 0.096 & 0.39 & 7038 \\
\hline & $45-54$ & 177,304 & 0.096 & 0.37 & 6294 \\
\hline & $55-64$ & 140,905 & 0.096 & 0.323 & 4364 \\
\hline & $65-74$ & 89,726 & 0.096 & 0.243 & 2092 \\
\hline & 75-100 & 93,117 & 0.096 & 0.145 & 1299 \\
\hline \multirow{7}{*}{$\begin{array}{l}\text { Psychological } \\
\text { disorders }\end{array}$} & $17-24$ & 374,800 & 0.224 & 0.108 & 9032 \\
\hline & $25-34$ & 376,800 & 0.224 & 0.102 & 8622 \\
\hline & $35-44$ & 397,500 & 0.224 & 0.097 & 8663 \\
\hline & $45-54$ & 351,600 & 0.224 & 0.09 & 7087 \\
\hline & $55-64$ & 190,200 & 0.224 & 0.074 & 3165 \\
\hline & $65-74$ & 70,000 & 0.224 & 0.051 & 804 \\
\hline & 75-100 & 36,800 & 0.224 & 0.028 & 230 \\
\hline Total & & & & & 140,073 \\
\hline
\end{tabular}

Note: DALYs are estimated using the standard formula (3) for each illness by age group

\section{Abbreviations}

BoD: Burden of disease; CRP: Challenging Racism Project; DALY: Disability adjusted life years; DFO: Dual-frame Omnibus Survey; EOD: Experience of racial discrimination; GBD: Global burden of disease; GDP: Gross domestic product; MSC: Mapping Social Cohesion; OR: Odds ratio; PAF: Population attributable fraction; PTSD: Post-traumatic stress disorder; RR: Risk ratio; VSL: Value of statistical life; WHO: World Health Organisation

\section{Acknowledgements}

We would like to thank Jehonathan Ben and Lennert Veerman for their valuable comments and assistance at different stages of the data analyses. We also would like the three reviewers of our manuscript for their helpful comments.

All the data that are used in this study are publicly available online except the following for which permissions were obtained from their owners: 1. Challenging Racism Project survey from Professor Kevin M. Dunn, University of Western Sydney, Sydney, Australia. 
2. Mapping Social Cohesion survey from Professor Andrew Markus, Monash University, Melbourne, Australia.

3. SRC Dual Frame Omnibus from the Social Research Centre, Melbourne, Australia.

4. Meta-analytic data for association of EOD and health available from the authors.

\section{Funding}

The first author was supported by an Australian Postgraduate Award (Industry) as part of linkage project (LP100200057) funded by the Australian Research Council, Victorian Health Promotion Foundation and the Australian Human Rights Commission. The second author is supported by an Australian Research Council Future Fellowship grant (FF130101148).

\section{Availability of data and materials}

The datasets analysed in this study are available from the corresponding author on reasonable request.

\section{Authors' contributions}

AE conducted a review of the literature, participated in data collection, performed the statistical and cost analysis, and drafted and revised the manuscript. YP led and participated in the study design and data collection, coordinated the statistical analysis, and helped in drafting the manuscript and critically reviewed it. Both authors read and approved the final manuscript.

\section{Competing interests}

The authors declare that they have no competing interests.

\section{Consent for publication}

Not applicable

Ethics approval and consent to participate

Not applicable

Received: 24 August 2016 Accepted: 23 November 2016

Published online: 29 November 2016

\section{References}

1. Feagin JR, McKinney K. The many costs of racism. Lanham: Rowman and Littlefield Publishers; 2003.

2. Harris R, Tobias M, Jeffreys M, Waldegrave K, Karlsen S, Nazroo J. Effects of self-reported racial discrimination and deprivation on Maori health and inequalities in New Zealand: Cross-sectional study. Lancet. 2006;367:2005-9.

3. Paradies Y. Ethnicity and Public Health: a systematic review of empirical research on self-reported racism and health. Int J Epidemiol. 2006;35:888-901.

4. Chrobot-Mason D, Ragins BR, Linnehan F. Second hand smoke: ambient racial harassment at work. J Manag Psychol. 2013;28:470-91.

5. Grigg K, Manderson L. Is there a relationship between psychopathic traits and racism? Curr Psychol. 2014;1-16. doi:10.1007/s12144-014-9283-9.

6. Kwate NOA, Goodman MS. An empirical analysis of White privilege, social position and health. Soc Sci Med. 2014;116:150-60.

7. Samson FL. Racial resentment and smoking. Soc Sci Med. 2015;126:164-8.

8. Halim ML, Yoshikawa H, Amodio DM. Cross-generational fffects of discrimination among immigrant mothers: perceived discrimination predicts child's healthcare visits for illness. Health Psychol. 2013;32:203-11.

9. Priest $N$, Paradies $Y$, Stevens M, Bailie R. Exploring relationships between racism, housing and child illness in remote Aboriginal communities. J Epidemiol Community Health. 2012;66:440-7.

10. Tran AG. Family contexts: parental experiences of discrimination and child mental health. Am J Community Psychol. 2014;53:37-46. doi:10.1007/ s10464-013-9607-1.

11. Triana MC, Jayasinghe M, Pieper JR. Perceived workplace racial discrimination and its correlates: a meta-analysis. J Organ Behav. 2015;36(4): 491-513.

12. Goto JB, Couto PFM, Bastos JL. Systematic review of epidemiological studies on interpersonal discrimination and mental health. Cad Saude Publica. 2013;29:445-59.

13. Johnston DW, Lordan G. Discrimination makes me sick! An examination of the discrimination-health relationship. J Health Econ. 2012;31:99-111.
14. Paradies $Y$, Ben B, Denson N, Elias A, Priest N, Pieterse A, et al. Racism as a determinant of health: a systematic review and meta-analysis. PLoS One. 2015;10(9):e0138511.

15. Pascoe EA, Richman LS. Perceived discrimination and health: a meta-analytic review. Psychol Bull. 2009;135:531-54.

16. Schmitt MT, Branscombe NR, Postmes T, Garcia A. The consequences of perceived discrimination for psychological well-being: a meta-analytic review. Psychol Bull. 2014;140:921-48. http://dx.doi.org/10.1037/a0035754.

17. Arrow KJ. Some mathematical models of race discrimination in the labor market. In: Pascal AH, editor. Racial discrimination in economic life. Santa Monica: The Rand Corporation; 1971.

18. Becker GS. The economics of discrimination. Seconth ed. Chicago: University of Chicago Press; 1971

19. Altonji JG, Blank RM. Race and gender in the labor market. In: Ashenfelter O, Card D, editors. Handbook of labor economics, vol. 3. 1999. p. 3143-259.

20. Blank RM, Dadaby M, Citro CF. Measuring racial discrimination. Washington: The National Academies Press; 2004.

21. Darity WA, Mason PL. Evidnece on discrimination in employment: codes of color, codes of gender. J Econ Perspect. 1998;12:63-90.

22. Kain, JF, Quigley JM. Introduction, In Housing markets and racial discrimination: a microeconomic analysis. New York: National Bureau of Economic Research; 1975. pp. 1-8

23. Yinger J. Closed doors, opportunities lost: the continuing costs of housing discrimination. New York: Russell Sage Foundation Publications; 1995

24. Brimmer AF. The economic cost of discrimination against black Americans. In: Virginia M, Simms MC, editors. Perspectives on affirmative action. Washington: Joint Center for Political and Economic Studies, Inc.; 1995.

25. Joint Economic Committee. The cost of racial discrimination. Washington: $U$. S. Government Printing Office; 1980.

26. Turner A. The Business Case for Racial Equity. National Civic Review. 2016; 105(1):21-29.

27. Drummond MF, Sculpher MJ, Torrance GW, O'Brien BJ, Stoddart GL. Methods for the economic evaluation of health care programmes. 3rd ed. Oxford: Oxford University Press; 2005.

28. Rice DP. Cost of illness studies: what is good about them? Inj Prev. 2000;6: 177-9. doi:10.1136/ip.6.3.177.

29. WHO. Global health risks: mortality and burden of disease attributable to selected major risks. Geneva: World Health Organization; 2009.

30. Lopez AD, Mathers CD, Ezzati M, Jamison DT, Murray CJ. Global and regional burden of disease and risk factors, 2001: systematic analysis of population health data. Lancet. 2006;367:1747-57.

31. Habtegiorgis $A E$, Paradies $Y$. Utilising self-report data to measure racial discrimination in the labour market. Aust J Labour Econ. 2013:16:5-41.

32. Bobo LD, Suh SA. Surveying racial discrimination: analysis from a multiethnic labour market. In: Bobo LD, Oliver ML, Johnson JJH, Abel Jr V, editors. Prismatic metropolis: inequality in Los Angeles. New York: Russell Sage; 2000. p. 523-60.

33. Nielsen LB, Nielsen RL. Scaling the pyramid: a sociolegal model of employment discrimination litigation. In: Nielsen LB, Nielsen RL, editors. Handbook of employment discrimination research: rights and realities. Dordrecht: Springer; 2005. p. 3-34.

34. Smith TW. Measuring racial and ethnic discrimination. Chicago: National Opinion Research Center; 2002.

35. Bertrand M, Mullainathan S. Do people mean what they say? Implications for subjective survey data. Am Econ Rev. 2001;91:67-72.

36. Kaiser CR, Major B. A social psychological perspective on perceiving and reporting discrimination. Law Soc Inquiry. 2006;31:801-30.

37. Krieger N, Carney D, Lancaster K, Waterman PD, Kosheleva A, Banaji M. Combining explicit and implicit measures of racial discrimination in health research. Am J Public Health. 2010;100:1485-92.

38. Challenging Racism Project 2012. Research. Accessed 24 Jan 2013: https:// www.westernsydney.edu.au/challengingracism/challenging_racism_project.

39. Markus A. Mapping social cohesion 2013: national report. Melbourne: the Scanlon Foundation Surveys; 2013. Accessed 24 Nov 2014 http://www.arts. monash.edu.au/mapping-population.

40. Hammen C. Stress and depression. Annu Rev Clin Psychol. 2005;1:293-319.

41. Stunkard AJ, Faith MS, Allison KC. Depression and obesity. Biol Psychiatry. 2003;54:330-7.

42. Zhang J, Yu KF. What's the relative risk? A method of correcting the odds ratio in cohort studies of common outcomes. JAMA. 1998;280:1690-1. 
43. Davies HTO, Crombie IK, Tavakoli M. When can odds ratios mislead? Biomed J. 1998:316:989-91.

44. Pepe MS, Janes $H$, Longton $G$, Leisenring W, Newcomb P. Limitations of the odds ratio in gauging the performance of a diagnostic, prognostic, or screening marker. Am J Epidemiol. 2004;159:882-90.

45. Mathers CD, Vos ET, Stevenson CE, Begg SJ. The burden of disease and injury in Australia. Bull World Health Organ. 2001;79:1076-84.

46. Mathers CD, Bernard C, Iburg KM, Inoue M, Fat DM, Shibuya K, et al. Global Burden of Disease in 2002: Data sources, methods and results, Global Programme on Evidence for Health Policy Discussion Paper No. 54. Geneva: World Health Organization; 2003 (Revised February 2004).

47. Begg S, Vos T, Barker B, Stevenson C, Stanley L, Lopez AD. The burden of disease and injury in Australia 2003. Canberra: AlHW; 2007.

48. Cohen AJ, Anderson RH, Ostro B, Pandey KD, Krzyzanowski M, Künzli N. The global burden of disease due to outdoor air pollution. J Environ Health Toxicol Part A. 2005;68:1301-7.

49. Rehm J, Mathers C, Popova S, Thavorncharoensap M, Teerawattananon Y, Patra J. Global burden of disease and injury and economic cost attributable to alcohol use and alcohol-use disorders. Lancet. 2009;373:2223-33.

50. Albert MA, Cozier Y, Ridker PM, Palmer JR, Glynn RJ, Rose L. Perceptions of race/ethnic discrimination in relation to mortality among black women. Arch Intern Med. 2010;170:896-904.

51. Deshaies P, Gonzales Z, Zenner H, Plontke S, Paré L, Hébert S, et al. Environmental Noise and Tinnitus. In: Theakston, F., editor. Burden of disease from environmental noise, Quantification of healthy life years lost in Europe. Copenhagen: World Health Organization. 2011. p. 71-85.

52. Cutler DM, Richardson E. The value of health: 1970-1990. Am Econ Rev. 1998;88:97-100

53. Miller P, Mulvey C, Norris N. Compensating differentials for risk of death in Australia. Econ Rec. 1997;73:363-72.

54. Nordhaus WD. The Health of Nations: the contribution of improved health to living standards. NBER Working Paper No. 8818. Cambridge: National Bureau of Economic Research; 2002.

55. Viscusi WK, Aldy JE. The value of a statistical life: a critical review of market estimates throughout the world. J Risk Uncertain. 2003;27:5-76.

56. Andersson $\mathrm{H}$, Treich $\mathrm{N}$. The value of a statistical life. A handbook of transport economics, vol. 17. 2011. p. 396.

57. Access Economics. The cost of domestic violence to the Australian economy: part I. 2004.

58. Piccinelli M, Wilkinson G. Gender differences in depression. Br J Psychiatry. 2000;177(6):486-92.

59. Massey DS, Lundy G. Use of Black English and racial discrimination in urban housing markets new methods and findings. Urban Aff Rev. 2001;36(4):452-69.

60. Angst J, Gamma A, Gastpar M, Lépine J-P, et al. Gender differences in depression. Eur Arch Psychiatry Clin Neurosci. 2002;252(5):201-9.

61. Kessler RC, Mickelson KD, Williams DR. The prevalence, distribution, and mental health correlates of perceived discrimination in the United States. J Health Soc Behav. 1999;40:208-30.

62. Utsey SO, Chae MH, Brown CF, Kelly D. Effect of ethnic group membership on ethnic identity, race-related stress and quality of life. Cultur Divers Ethnic Minor Psychol. 2002;8(4):366.

63. Mathers CD, Stevenson C, Carter R, Penm R. Disease costing methodology used in the Disease Costs and Impact Study 1993-94. AHW cat, no. HWE 7. Canberra: Australian Institute of Health and Welfare, (Health and Welfare Expenditure Series no. 3); 1998.

64. Gee G, Walsemann K. Does health predict the reporting of racial discrimination or do reports of discrimination predict health? Findings from the National Longitudinal Study of Youth. Soc Sci Med. 2009;69:1676-84.

65. Dolezsar CM, McGrath JJ, Herzig AJM, Miller SB. Perceived racial discrimination and hypertension: a comprehensive systematic review. Health Psychol. 2014;33(1):20.

66. Vos T, Mathers CD. The burden of mental disorders: a comparison of methods between the Australian burden of disease studies and the Global Burden of Disease study. Bull World Health Organ. 2000;78:427-38.

67. Australian Bureau of Statistics. National Survey of Mental Health and Wellbeing: Summary of Results, cat no. 4326.0, Canberra, 2007.

68. Australian Institute of Health and Welfare. Chronic Diseases and Associated Risk Factors in Australia 2006. Canberra: AlHW; 2006.

69. Mathers C, Fat DM, Boerma JT. The global burden of disease: 2004 update Geneva: World Health Organization; 2008.

70. Australian Institute of Health and Welfare. Health expenditure Australia 2011-12 Health and welfare expenditure series No. 50. Cat. No. HWE 59. Canberra; 2013.
71. Australian Institute of Health and Welfare. Australia's health 2012. Australia's health series no.13. Cat. No. AUS 156. Canberra: AlHW; 2012.

72. World Bank. GDP (Constant LCU), World Development Indicators, World Bank Group. 2015.

73. Kwate NOA. 'Racism Still Exists': a public health intervention using racism 'Countermarketing' outdoor advertising in a black neighborhood. J Urban Health. 2014;91:851-72.

\section{Submit your next manuscript to BioMed Central and we will help you at every step:}

- We accept pre-submission inquiries

- Our selector tool helps you to find the most relevant journal

- We provide round the clock customer support

- Convenient online submission

- Thorough peer review

- Inclusion in PubMed and all major indexing services

- Maximum visibility for your research

Submit your manuscript at www.biomedcentral.com/submit
Biomed Central 